IBIMA Publishing

The MENA Journal of Business Case Studies

http://www.ibimapublishing.com/journals/MENA/mena.html

Vol. 2015 (2015), Article ID 636015, 11pages

DOI: $10.5171 / 2015.636015$

Research Article

\title{
Toilet Soap Case
}

\section{Engy El Maghraby and Ahmed Tolba}

The American University in Cairo, Egypt

Correspondence should be addressed to: Ahmed Tolba; ahmedtolba@aucegypt.edu

Received date: 21 March 2015; Accepted date: 6 April 2015; Published date: 28 December 2015

Academic Editor: Susana de Juana-Espinosa

Copyright (C) 2015. Engy El Maghraby and Ahmed Tolba. Distributed under Creative Commons CC-BY 4.0

\begin{abstract}
Mayer Brothers is a famous FMCG company that launched in the year 1920 as a merger between a British soap maker and a Dutch margarine producer, to increase efficiency of resources. Having entered the Egyptian market in the year 1991, the company needed to make certain adjustments to its products on the basis of the specific Egyptian market and the culture of the Egyptian people. Despite the fact that the world has been shifting its purchase patterns towards the gel and liquid soaps, many Egyptians (especially of lower socio-economic classes) have still been clinging to the old bar soaps for all kinds of cleansing rituals. In order to maintain a balance between keeping up with modern-day trends, as well as preserving the Egyptian consumer base, Mayer Brothers must scrutinize the market at hand in order to come up with the best possible market strategy for the coming three years.
\end{abstract}

Keywords: FMCG, Soap, Egyptian market

\section{Toilet Soap Industry in Egypt \\ Mayer Brothers at Cross Roads}

It was a late afternoon in Cairo on December $6^{\text {th }}, 2010$, when Ms. Nada Habib, Head of Marketing at Mayer Brothers (MB), was sitting in her office in Maadi, Cairo, looking at the latest share reports for Toilet Soap. Since 2008, the imported Emirati brand, Marina, had been growing continuously in shares on the expense of Mayer Brothers' brands, as well as its key competitor Tri-Star. Ms. Habib thought about how this brand had managed to grow and capture shares in such a stagnant market, with no apparent advertising or obvious consumer support. She had planned a marketing campaign for Venus- a beauty brand that was due for launch in the first quarter of the year 2011. Deep down however, she understood that this would not be a long term cure for her category. The Mayer Brothers board of directors asked her to develop a three-year plan to deliver sustainable, double digit growth. Accordingly, she needs to submit her plan by January, and as 2011 approaches quickly, she ponders on how to utilize her different brands and product ranges to win in this dynamic market, and stop competition from growing on her expense.

Cite this Article as: Engy El Maghraby and Ahmed Tolba (2015), "Toilet Soap Case" The MENA Journal of Business Case Studies, Vol. 2015 (2015), Article ID 636015, DOI: 10.5171/2015.636015 


\section{Company Background}

Mayer Brothers is a famous FMCG company that started in the year 1920 as a merger between a British soap maker and a Dutch margarine producer, to increase efficiency of resources, specifically in the area of importing palm oil (a key raw material in both products). The company has a leading edge in the field of fast moving consumer goods with 400 brands sold in over 150 countries. These brands mainly fall under two categories: food and beverages, and home and personal care (Check Exhibit \#1 for company portfolio). Mayer Brothers started 20 years ago in Egypt, as a joint venture between the giant multinational and an Egyptian company. The company operates in seven different categories, maintaining its leadership in most. Taking a closer look at the skin cleansing category, the company offers a portfolio of four different brands to respond to the different consumer needs: Venus, which holds strong equity based on softness; Shams, which has a key selling proposition being the lowest price point brand; Ivory, the skin care brand, which is differentiated as being a creamy soap bar; and finally Shepherd, the recently launched hygiene soap brand.

\section{Egypt's Macroeconomic Profile}

Mayer Brothers operates in Egypt- a strategic location for international trade. Egypt's economy is heavily dependent on the services sector, primarily tourism. The services sector makes for $48.7 \%$ of the country's GDP, followed by industry at $37.6 \%$, and finally agriculture, at $13.7 \%$. The claimed unemployment rate in Egypt is 9\%, although according to experts the reality could be as high as $20 \%$. The Egyptian government had started a set of economic and financial reforms in 2004, leading to an increase in the volume and value of trading, ultimately attracting more foreign direct investment. These reforms include adding a set of rules for cash flows, and fixing issues related to market credibility and settlement of loans, privatizing major public companies, and recapitalizing insurance companies. The Egyptian economy experienced an accelerated GDP growth rate between 2004 and 2008, with GDP growth reaching $7 \%$.
After the financial crisis, this rate of growth declined to between 4.5 and 5.5\% annually (not bad in relation to the rest of the world). The Egyptian economy was merely mildly affected by the global financial crisis due to the conservative local financial sector, and the absence of many of the complicated financial factors that led to the crisis. Egypt is, however, experiencing an increased rate of inflation, with a latest estimate of $11.8 \%$, and frequent shortages of food and other commodities.

Furthermore, the inflation was coupled with an increased stress on the country's infrastructure and resources in direct correlation with the increasing population. The fact is that there is also a lack of transparency when it comes to certain policies, such as the energy and subsidy policies. The energy subsidies represent a major component in the Egyptian economy, worthy of consideration seeing as how it affects all other sectors. The subsidy give to the petroleum products increased from 10.2 Billion EGP in 2001 to 40.1 Billion EGP in 2006, and then to 62.7 Billion EGP in 2009 (According to Dr Ola Hakeem in an interview with Al Yaum Al Sabe' newspaper on 9th of November 2010). The diesel subsidies are specifically the most important given that it is the main fueling source for public transportation vessels. Ultimately, its price increase leads to increase in prices of all other commodities. The diesel price doubled twice in the past 3 years (not due to market increase but to the reduction of subsides by half the price) with a subsequent increase in food and transportation prices. The current diesel price is still subsidized with its current price of about half of its real market price. This, in turn, increases the risk of similar subsidy lifting actions, which could further increase food \& commodity prices.

\section{Global Toilet Soap industry}

Globally, the toilet soap industry is growing at a constant rate, and is expected to continue to grow at an average of $5 \%$ (Parker). While the bar soap market either remains stagnant or declines, shower gels and hand wash continue to grow at a rapid rate as the market develops into more premium innovations (Hendarwan). Liquids 
in general maintain a higher share in developed markets compared to emerging markets. This is due to the higher PPP as well as the early market development that took place, which made developed markets receptive to changing usage behaviors and switching to the more premium products.

\section{Toilet Soap industry in Egypt}

Until 2006, the toilet soap market in Egypt has had been growing by $3 \%$ on volume, and $7 \%$ on value, driven by the downsizing of main multinational players. This is directly correlated to the manufacturers' downsizing of the sold products, given that consumers will always be found to buy more of the smaller product, on a more frequent basis. Thus, the sales value for soap bars continued to increase until the year 2007. The market has declined by $6 \%$ and has been stagnant on sales value ever since. The main reason for the volume decline was the dropping frequency of consumption after the price increases were taken by all major players in 2008, after the bio-fuel price increased. Another reason behind the decline was the growth of other soap formats, such as liquid soap and shower gels, although their growth was not large enough to compensate for the decline in soap bars. In 2010, however, the market has shown minimal growth of $5 \%$ due to the increased consumption of disinfectant soap after the swine flu burst.

The market is currently divided into 3 main segments: soap bars (value brands and premium brands), shower gels, and hand wash. Value brands of soap contribute to over $50 \%$ of the volume sold in the market, followed by premium brands, and finally shower gels and hand wash (representing a mere $7 \%$ of the market volume) (See Exhibit \#3). However, on the value parameter, liquids make for $10 \%$ of the market sales value, since the price per gram is much higher. This reflects the potential of the new emerging market. Loyalty in the value segment is very low, due to the fact that consumers merely look for a price per size mix that suits their need. Accordingly, the value brand equity is very low, unlike the case for the premium brands. Equity of premium brands maintains a strong basis due to years of advertising as well as both the functional and emotional benefits that contribute to improving these brands' consumer conviction \& loyalty.

\section{Key Players in the Market}

The toilet soap industry in Egypt is considered to be a fragmented and stagnant industry, due to the existence of several international and local players in the market. Furthermore, the fact remains that the soap market is stagnant in volume due to lower usage frequency and conversion to bigger bars. Until 2007, Mayer brothers maintained market leadership with their 3 brands, namely: "Venus," "Shams" and "Ivory". Then in 2009 the company launched its hygiene brand, Shepherd. The key competitors for Mayer Brothers in the toilet soap category are: Tri-Star, a major multinational FMCG, which manufactures the beauty brand "Crystal" and the hygiene brand "Anchor", recently launched in 2009. Tri-star used to hold a significant fifth of the market share, with Crystal alone. The third multinational player in the soap market is Green Corp, which is also active in detergents, dish washing liquid, and deodorants. Green Corp used to claim around 10\% market share with its brand "Aqua" until it downsized its size by $17 \%$ to $50 \mathrm{gm}$ in 2006 , leading to their major share loss. Kremer Group is the fourth multinational company, providing products in personal care and home care, mostly under the antiseptic brand "Victor". Last but not least is Labib Fathy Labib- the key importer in the soap market, introducing Marina- a soap brand manufactured by the Emirati Company Mefco. In a mere 3 years, Marina managed to engulf one sixth of the market. (Check Exhibit \#2 for main brands in the market and their positioning).

\section{Distribution}

The market is divided into four main regions: Greater Cairo, Alexandria, Delta and Upper Egypt (check Exhibit \#4 for market sales volume by geographic area). Cairo and Delta represent the major bulks of the market, with over 65\% market shares, followed by Upper Egypt with $20 \%$ market share, and finally Alexandria with around $10 \%$ market share. Multinational brands are more dominant in Cairo and Alexandria, although imported 
brands are also growing vigorously in Delta. Delta has a special nature due to the large number of governorates and the diversity of consumer needs, which creates an attractive market to importers. In fact, the growing trend of Turkish and Emirati brands has originated from Delta. Upper Egypt on the other hand, is dominated by the small sized value brands, due to the lower purchasing power parity.

The retail market for toilet soap is divided into four main selling channels: hyper markets and supermarket chains, groceries, detergent shops (Sabanat), and pharmacies. Groceries and detergent shops represent over $70 \%$ of the soap market, followed by supermarkets, which represent around 15\% of the market sales. Pharmacies are considered a specialized format, mainly selling hygiene and skin care brands. Manufacturers sell almost $70 \%$ of their products to wholesalers, who in turn distribute to the above mentioned retail channels (except for the case of supermarkets, which are served directly). Hyper markets are mainly found in Cairo and Alexandria, and they offer a variety of brands across all categories. On the other hand, smaller retailers, such as groceries and detergent shops, tend to carry a limited number of brands across all the categories that they deliver. The reason is that small retailers have a limited cash supply, and therefore prioritize the fastest moving brands over others. Each of the above 2 main selling channels has its own advantages. Shopping trips to hyper markets are usually made on a monthly basis. Shoppers in this case are looking for the variety and offers they would not find elsewhere. Ultimately, hyper market shoppers are mostly from a higher socio-economic class in order for them to be able to afford this type of a shopping trip. Manufacturers are compelled to give special offers to hyper markets to be able to face the large number of competitors. Nonetheless, shoppers from lower socio economic classes as well as those from Delta and Upper Egypt, seek the convenience and proximity of grocery and detergent shops. These shops are usually located close to shoppers' houses, ensuring that the shoppers have strong relationships with shop owners, and trust their recommendations when it comes to which products to buy.

\section{Consumer \& Shopper Behaviour}

Consumers in Egypt, who consider toilet soap to be an essential personal care product, look for certain qualities when evaluating a certain soap brand. These qualities affect their decision-making process as well as their usage behavior. The qualities are: perfume, lather, softness, lasting, and value for money. In the lower socio-economic classes, consumers use soap bars as their ultimate personal care product, not only as a soap bar for cleansing and bathing, but also as a shampoo, deodorant, and tooth paste. This fact explains why long lasting perfume and large amounts of lather become very important. In the lower-classed regions, mothers consider bathing to be an essential procedure for kids before they leave the house and right when they get back, the reason being that clean kids are a reflection of mothers' competence. After the general price increase on most commodities in the years 2007 and 2008, pricing became a major concern for consumers, especially of the lower social class. Consumers were finally ready to pay more so as to receive a better value.

Consumers are not always the shoppers. In most cases, grocery shoppers are the female members of the family, and it is they who make the household's commodity decisions. Even in the situations in which the mother would send someone other than herself to make the purchases, she would still make the brand choices. Because of the declining purchasing power, shoppers are becoming more like hunters, seeking to find best offers, and the greatest value. Some behavioral patterns noticed among shoppers are that: they smell the soap bars to evaluate the strength of the perfume. Egyptian shoppers also have a tendency to like dark colors of packaging (especially black), and that applies not only to soap, but to other personal care products as well. Shoppers shop once a month, buying in bulk all that their household needs. When the supply ends halfway through the month, however, that is when they buy individual items. Shoppers, who shop at hyper markets, consider the 
shopping trip to be an outing, exposing them to all the special offers that the large variety hyper markets are eager to offer.

\section{Market Dynamics Early 2000s}

During the early 2000s, the largest segments in the market were the $60 \mathrm{gm}$ and $80-125 \mathrm{gm}$ size bars, making for over $50 \%$ of the market. Mayer brothers, Tri-Star, and Green Corp brands all fell within this category. Sizes larger than $125 \mathrm{gm}$ were perceived to be unnecessarily big, and smaller sizes below $60 \mathrm{gm}$ were considered to be a waste of money. Looking at the brand's performance, Mayer Brothers claimed unprecedented market leadership with their products: Venus and Shams (Shams alone held 25\% of the market sales volume, while Venus was the number one beauty brand). Shams was priced at the lowest price point in the market with relatively good quality; thus, it was the soap bar everyone could afford. Venus, likewise, was delivering on both functional and emotional attributes. The product performance was well perceived by its target market, and was strongly delivering on softness, stressing on this attribute using a female star into the advertisements. Egyptian/Arab stars (such as Raghda, Mona Zaki, Someya El Khashab, and Elissa) were incorporated into the Venus advertisements during the 2000s period. Crystal, the main competitor, however, consistently used a copy focusing on male and female attraction by the female's French, long lasting perfume. During the period from 2005 to 2007, Crystal started rising until it reached parity with Venus. On the other hand, Aqua used to hold around $10 \%$ of the market until it downsized its $60 \mathrm{gm}$ bar to $50 \mathrm{gm}$, leading to a major share loss as consumers ceased to find its value for money. (Check Exhibit \#5 for Brands performance between 2005 to 2010)

\section{The Oil Crisis in 2006-2007}

In 2006, with the inflation witnessed in crude oil prices, demand has increased on bio-fuels, leading to a major rise in prices. Bio-fuels (such as palm and sun flower oils) are a major component to the materials used to manufacture toilet soap. The oil hit has led to an increase in material costs of several manufactured consumer goods by over $50 \%$ in 2006, and is expected to continue rising. Companies that manufacture products such as cooking oil, rice, sugar, toilet soap, and detergents, were either to operate under loss and or manage under amplified pressure to increase their end consumer prices to sustain profitability. Enduring price increases was never a preferred job for companies, and was always faced with severe resistance from both consumers and trade. Consumers, by default, would resist the increases and might search for other alternatives that provide them with the same value they are used to. Egyptians in particular, facing the current inflation at $11.8 \%$ (CIA World Fact Book), and rise in prices in almost every category, coupled with the stagnation of salaries, are expected to show a strong resistance to price increases. On the other hand, trade (which represents the intermediary between consumers and manufacturers), will also resist price increases seeing as how it will eventually lead to a slower movement of their working capital with the decreased purchases. All multinational manufacturers have had to increase the prices, and/or downsize, in order to sustain their profit margins. This, however, came at a loss. Mayer brothers lost mainly on Shams, since its main equity was the low price. With the price increase, consumers were ultimately pressured to resort to alternate brands that came in larger sizes and more value for money. Tri-Star and Green Corp lost as a result of downsizing their smallest sizes of Crystal and Aqua. Following the price increases, it was also witnessed that consumers began economizing their consumption of the different product categories that had the highest price increases- mainly soap, cooking oil, and ghee. Consumers where not cutting down on bathing, but they were controlling the quantities used to make their products last longer. Accordingly, while the market volume declined, the market value was slightly growing due to the price increases as well as the downsizing.

\section{Rising Trends in TS Market}

\section{Bigger Bars: Case of Marina}

Shortly before the oil price hit, a new trend grew in the market: the rise of bigger sized 
bars in Delta. This trend began in 2005, but particularly displayed a magnified magnitude by 2009 . What happened was that Egyptian importers introduced Turkish and Emirati soap bar brands into the retail market in the Delta region, and these brands picked up with both trade and consumers. The new bars were $40 \%$ bigger in size, but were still sold at almost an equal price to the multinational, smaller size brands. To penetrate trade, importers gave wholesalers and retailers a more competitive trading margin, thus encouraging them to carry these brands at their outlets and recommending them to their shoppers. Consumers in the Delta region tried the new brands out, maximizing their value for money by continuing to do so. Value for money, rather than price, became the decisive factor for making a purchase. Hence Therefore, consumers paid more to shift to bigger bars, which lasted longer on the sink. For them this was more economic because what remains (barwa) from a single $130 \mathrm{gm}$ soap bar is in fact half of what remains from two $65 \mathrm{gm}$ bars. Another reason was that these soap bars were imported, which gave them a higher aspiration appeal, given that Egyptian consumers have a soft spot for imported products. All in all, consumers claimed that these imported brands had strong long lasting perfume, large quantity of lather that lasted for long periods of time.

Marina, the Emirati brand, portrayed significant growth despite the general market decline. The interesting thing was that this brand had had no previous equity, and hadn't succeeding by means of the mainstream marketing techniques used by others (advertising, sampling, or even point of purchase materials). Marina grew through trade push and consumer word of mouth, which were clearly very powerful tools. When consumers tested the brand and liked it, they advocated it to their families, neighbors and friends. In the beginning consumers were ready to try other brands besides Marina, however later on the brand was able to develop loyalty, such that a portion of its consumers became unwilling to switch back to their original brands or try new offerings. While the Marina stronghold continued to be the Delta region, it still managed to grow in both Cairo and
Alexandria, beginning in 2008 onwards. In five years the brand captured almost one sixth of the total market, on the expense of other multinational brands using a business model entirely based on trading, and no direct operations have been implemented thus far. (Check Exhibit \#5 for Brands performance between 2005 and 2010).

Meanwhile, multinational companies began realizing the "value for money" concept that was affecting consumer changing behaviors, embracing the growing trend of bigger bars. However, by the time they had arrived at their conclusion, both Venus and Crystal had launched their $175 \mathrm{gm}$ bars in 2008 to utilize the opportunity in the declining market, supporting it with above the line communication. Shams also launched a $100 \mathrm{gm}$ bar to respond to the new trend, causing this to be the standard selling size. As bigger bars became more dominant, they started growing in market share on the expense of the smaller sizes (50-90gm). In terms of communication and promotions, the focus was to highlight the "bigger value," which was the most relevant message to consumers at the time. The "bigger bars" trend also picked up significantly in hyper and super markets in Cairo and Alexandria, due to the outlets' nature, where bigger sizes were preferred by shoppers in most categories. Multinational brands established themselves well in hyper and super markets, yet Marina sustained the lion share, and even grew at a higher rate compared to any other brand. Stopping Marina's rapid growth remains a major challenge, especially with the news that the Emirati manufacturer Mefco is planning to start direct operations in Egypt in 2011, posing an additional threat.

\section{Disinfectants Soap: Swine Flu}

Bigger imported soap bars did not constitute the only trend that hit the market in last 5 years. The burst of Swine Flu, which causes "seasonal outbreaks of flu in humans" ("Egypt Slaughters") appeared at the end of the year 2008, and had a major effect on the market dynamics. The continuous deaths reaching 224 of victims in one year caused a public panic, especially from schools and universities. Parents were worried about their children's safety, and kept them home 
from school. Moreover, all schools or and universities that had reported cases of swine flu were closed for a period of time, until they were rendered for operation. Despite the fact that Egypt was originally unprepared to combat this epidemic, in 2009 major PR campaigns sponsored by the ministry of health were launched to educate the public on how to avoid the infection. The communication constantly stressed the importance of frequent hand washing to kill germs that could cause the flu. Furthermore, schools started asking the parents to give a soap bar to their kids at school. It is therefore at that time that Victor, the disinfectant soap which has had been in the market for some time, had a major rise in share. Victor, manufactured in the UAE, went out of stock later in 2009 due to the rising and unexpected demand (check exhibit \#6 for growth of hygiene soap segment).

Both Tri-Star and Mayer brothers launched their disinfectant soap brands: Anchor and Shepherd, between late 2008 and mid 2009 respectively, to respond to the rising disinfectant soap trend. Victor remained on the lead in this segment, still all the three brands managed to gain share. What is noteworthy is that the communication, as well as market development initiatives encouraging more frequent usage, had a positive effect on consumer habits, leading to an increase in the market volume after a period of significant decline. The three brands launched PR campaigns focusing on the importance of using disinfectant soap several times a day to kill germs and protect oneself from diseases- especially Swine flu. The different campaigns incorporated the following strategies: advertising, sampling, sponsoring school activities, and copromoting with other brands. Consumers, especially mothers whose kids are their number one priority, responded favorably to these campaigns, resulting in a growth for the disinfectant soap segment. One important dimension that is worthy of cautious consideration, is the size of the opportunity in this segment, and the fierce competition of the other players, making investing behind Shepherd an option that needs careful quantification.

\section{Shower gel and Hand wash}

The rising trends in the dynamic toilet soap market were not confined to soap, since liquids and primarily shower gels have been relatively active in the market since the launch of the Venus shower gel in the year 2000. The liquids market represents a mere $7 \%$ because no market development activity took place on any brand (Check Exhibit \#3). Venus is a key player in the market, positioned to provide it's consumers with an indulging experience. The other key player is Sabina, which is a brand manufactured by Sina (a local company, focusing mainly on big sizes for cheap prices). Due to the fact that the product is still regarded as a luxury product, shower gels are distributed mainly in Cairo and Alexandria, in hyper markets, supermarkets and pharmacies. Crystal launched its shower gel in 2008 supported by the same communication it uses for soap bars. While the liquids market shows a lot of potential for the following reasons: it is underdeveloped, has higher profitability, and is growing by a much larger percentage compared to soap (Check Exhibit 7 for growth patterns of the toilet soap sub segments), the key players do not seem to be reaping such a potential. The liquids market, like any other unexplored market, requires patience and investment until companies are able to affect and change its consumer habits. As Ms Habib looks at the share reports, she wonders whether pouring more investment in liquids will be a viable decision.

\section{A Future Outlook}

Ms. Habib had to reflect on the above thoughts, while thinking about the threeyear-plan she needs to develop in order to grow in such a dynamic market. She was thinking about how to bring back the glory Venus used to possess, and what needs to be done for consumer conviction in the brand to return. She was also pondering on how the market is not growing at a high rate, and how competitor moves in soap are - continuous. Ms. Habib has to weigh all the options wisely and make a strategic allocation of resources among brands and product ranges, to make a sound plan to help her to win in such a dynamic and restless market. 


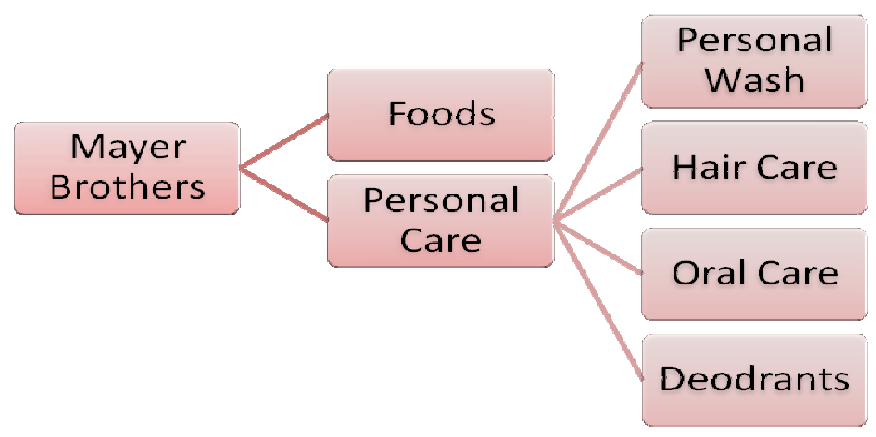

Figure 1: Categories in which Mayer Brothers Operates

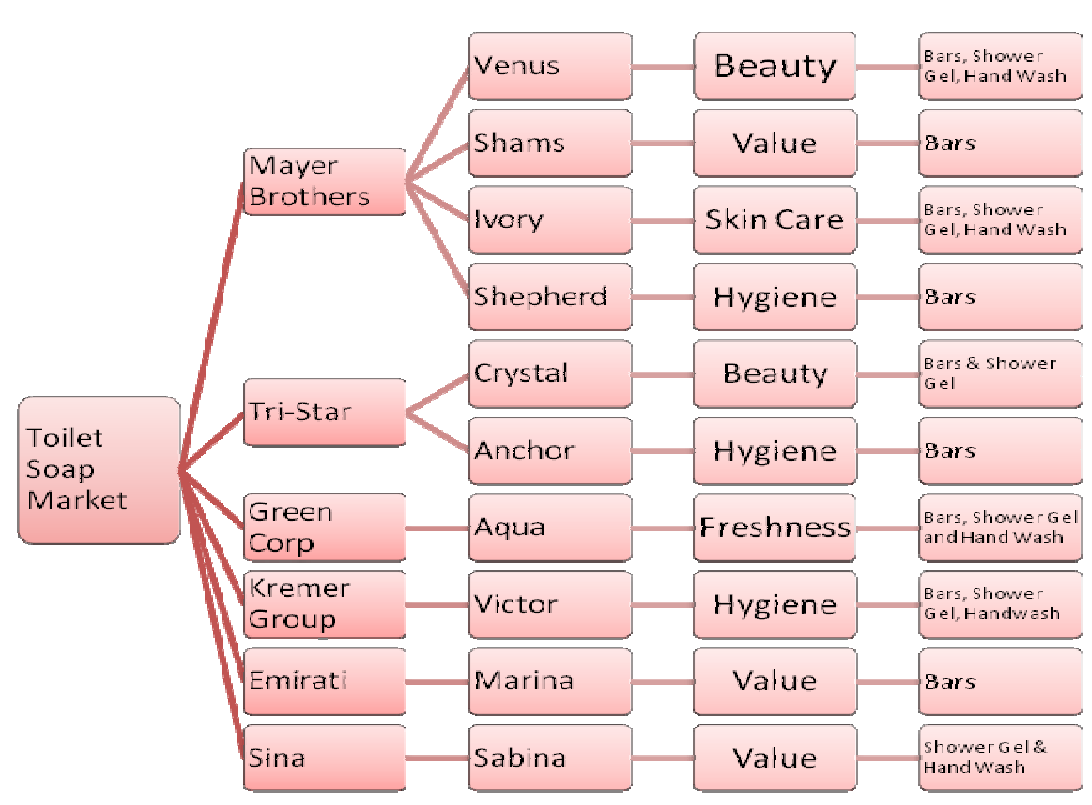

Figure 2: Key Players in the Toilet Soap Market 


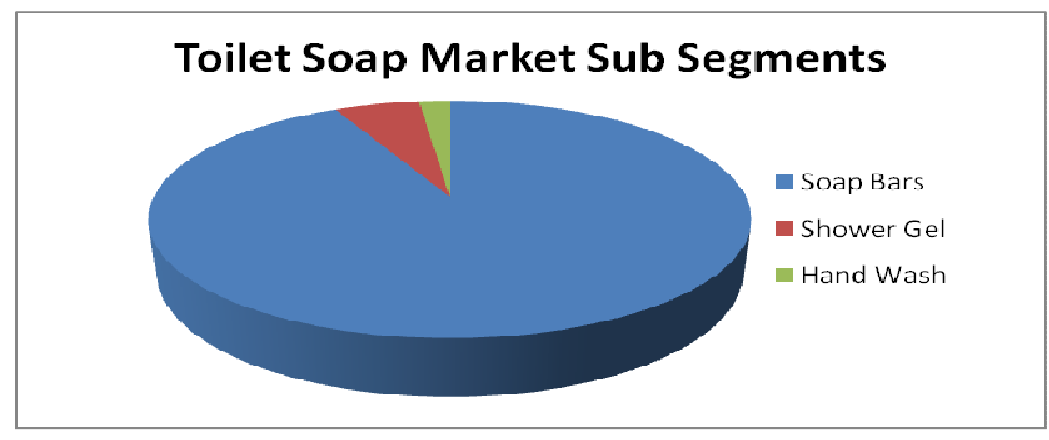

Figure 3: Toilet Soap Market Sub Segments

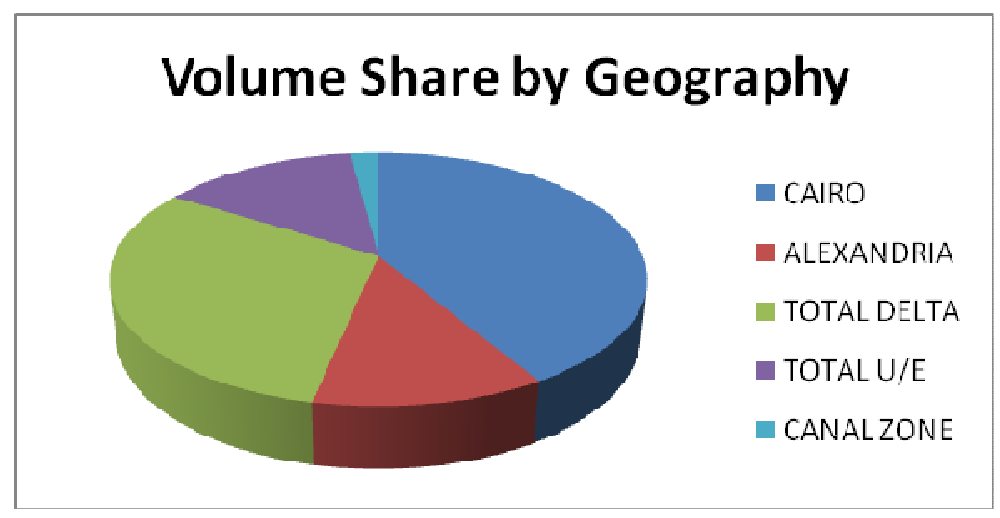

Figure 4: Market Contribution by geography

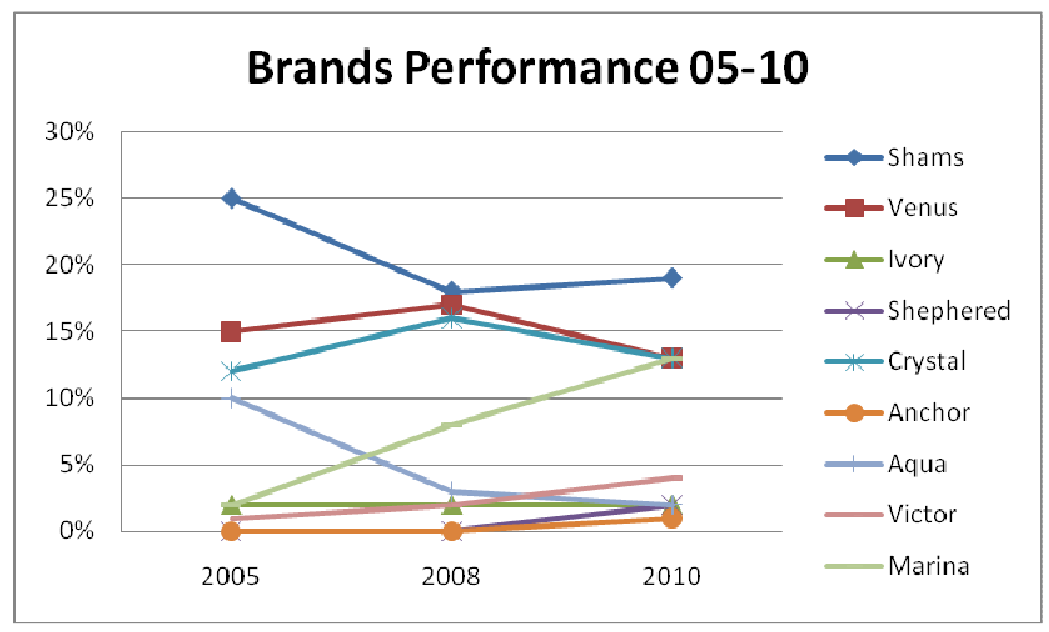

Figure 5: Brands Performance 2005 to 2010 


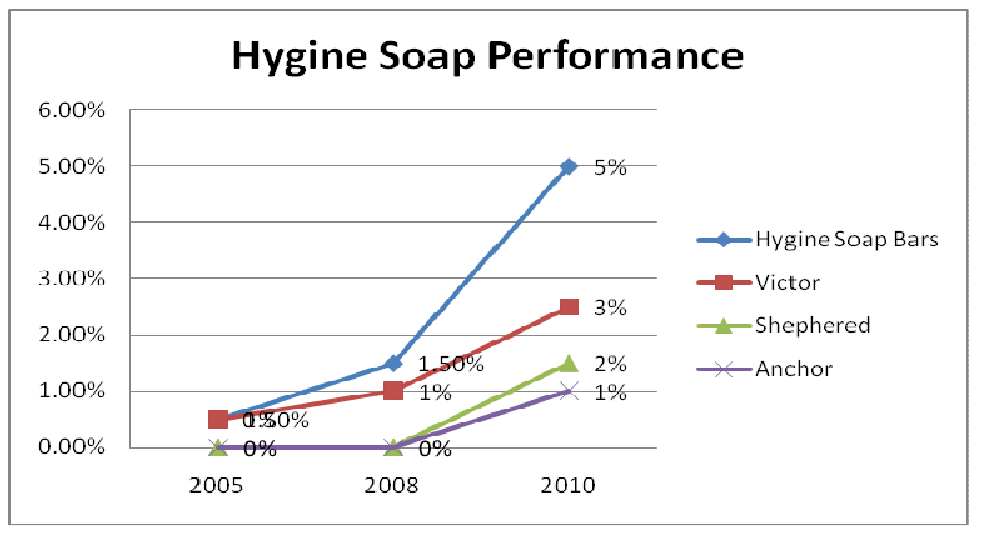

Figure 6: Growth of disinfectant soap

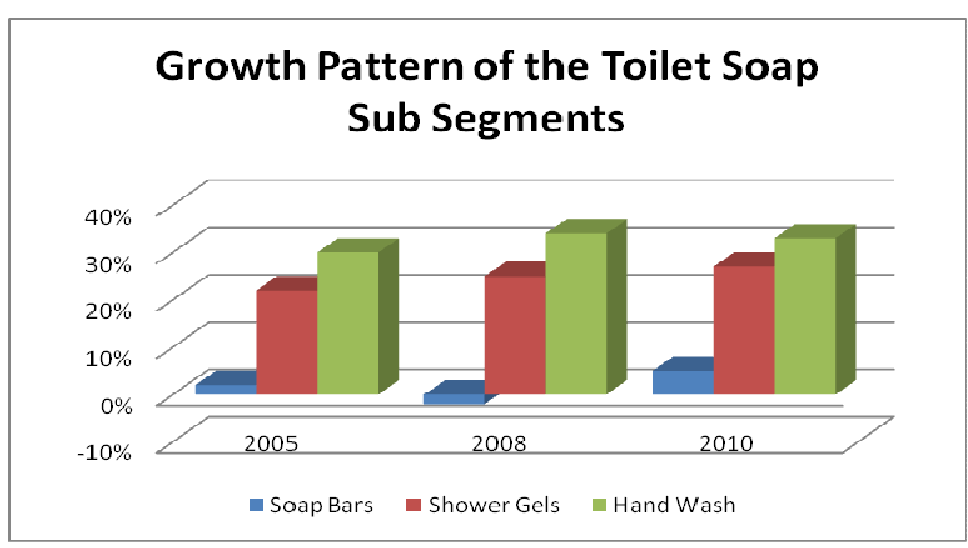

Figure 7: growth of Shower Gel and Hand Wash vs total market 


\section{Notes:}

${ }^{1}$ This is a real case, however the names of companies, brands and people are factionary and the shares have been manipulated for confidentiality purposes.

\section{References}

1. "Egypt Slaughters Pigs to Stop Flu" (29 Apr. 2009) BBC News. <http://news.bbc.co.uk/2/hi/8024946.stm>.

2. Hendarwan, Erlina "Every Day Bubble." (2002) World Market. EBSCO Publishing

1 The author wrote this case solely to provide material for class discussion the authors do not intent to illustrate either effective or ineffective handling of a managerial situation. The authors may have disguised certain names and other identifying information to protect confidentiality. KCC prohibits any form
3. Parker, Philip." The 2006-2011 World Outlook for Manufacturing Soap, Cleaning Compound, and Toilet Preparations" (2005) INSEAD (Singapore and Fontainebleau, France).

4. Mansour, Khaled. Personal Interview. Dec 2010 (Khaled Mansour is Shams and Shepherd brand Manager at Mayer Brother).

5. Mayer Brothers. "Annual Report and Accounts 2009"

"Mayer Brothers" (2010) Wikipedia.

of reproduction, storage or transmittal without its written permission. Reproduction of this material is not covered under authorization by any production rights organization.

Copyright 2011, KCC 